\title{
The "We Act"-Study: Design of a Multicomponent Intervention to Promote Healthy Diet, Physical Activity, and Well-being in School Children
}

\author{
Marianne S. Sabinsky ${ }^{1, *}$, Ane Høstgaard Bonde ${ }^{2}$, Nanna Wurr Stjernqvist ${ }^{2,3}$, \\ Elaine Jessen-Klixbüll ${ }^{1}$, Helle Terkildsen Maindal $^{2,4}$, Inge Tetens ${ }^{1,5}$ \\ ${ }^{1}$ Division for Diet, Disease Prevention and Toxicology, National Food Institute, Technical University of Denmark, \\ Kgs. Lyngby, Denmark \\ ${ }^{2}$ Steno Diabetes Center Copenhagen, Health Promotion Research, Gentofte Denmark \\ ${ }^{3}$ Division of Risk Assesment and Nutrition, National Food Institute, Technical University of Denmark, Kgs. Lyngby, Denmark \\ ${ }^{4}$ Department of Public Health, Aarhus University, Denmark \\ ${ }^{5}$ Vitality - Centre, for Good Older Lives, Department of Nutrition, Exercise, and Sports, University of Copenhagen, \\ Frederiksberg C, Denmark \\ *Corresponding author: masab@food.dtu.dk
}

Received July 17, 2018; Revised September 05, 2018; Accepted October 09, 2018

\begin{abstract}
Strategies to improve health behaviour and well-being of children are needed. A multicomponent intervention "We Act - together for health" was developed with the aim to improve the dietary habits, physical activity, well-being and social capital among school children aged 10-12 years by increasing their health competences and promoting a healthy school environment. This paper describes the theoretical frame for the project, the development of the We Act intervention and the design and methods used in the efficacy study. We Act builds upon the health promoting school approach and the IVAC model. The intervention included three components: 1) An educational component compromising: a) Lunch meal habits integrated into science and Danish ("IEAT"), and physical activity integrated into maths ("IMOVE"); b) Vision workshop integrated primarily in Danish, and; c) Action and Change process at class and school level. 2) A school component including a workshop to develop teachers' competencies, and 3) A parental component: including homepage, an APP, a Facebook-group and a handout produced by their child. A quasi-experimental study with 4 intervention schools and 4 matched control schools was conducted. In total 656 school children participated. The intervention was carried out in between the baseline and follow up measurements and a process evaluation was carried out to study implementation fidelity. Dietary intake during the school day was measured using a digital photographic method, pedometers registered physical activity, and an electronic questionnaire was used to assess well-being and social capital among the pupils. We Act will provide new knowledge on the implementation and effectiveness of a multicomponent school based intervention targeting school children, teachers, school management and parents to promote dietary habits, physical activity, and well-being among school children. An important part of the evaluation will be to sum up the various intervention components to inform stakeholders and health planning administrators.
\end{abstract}

Keywords: intervention, health promoting school, IVAC-model, dietary habits, physical activity, well-being, social capital

Cite This Article: Marianne S. Sabinsky, Ane Høstgaard Bonde, Nanna Wurr Stjernqvist, Elaine Jessen-Klixbüll, Helle Terkildsen Maindal, and Inge Tetens, "The "We Act"-Study: Design of a Multicomponent Intervention to Promote Healthy Diet, Physical Activity, and Well-being in School Children.” Journal of Food and Nutrition Research, vol. 6, no. 9 (2018): 602-613. doi: 10.12691/jfnr-6-9-10.

\section{Introduction}

Healthy nutritional and physical activity behaviour during childhood promotes optimal health, growth and cognitive development of the child, and may contribute to well-being and prevention of chronic disease in later life $[1,2]$. Some evidence suggests that health behaviour tracks from childhood into adulthood and that the extent to which an individual's health and well-being is constituted has consequences across the life-course [2,3,4].

According to recent Danish National Survey of Dietary Habits and Physical Activity [5] many Danish school children do not meet the official nutrition recommendations, dietary guidelines that also include guidelines for physical activity [6]. Data from the Danish cross-sectional Health Behaviour in School Children survey indicates that well-being among school children is worsening [7]. Thus, there is a need for health-promotion 
activities targeting children's health behaviour regarding food, physical activity, and well-being.

The school has been recognised as an important setting for health promotion as children spend around $40-50 \%$ of their waking hours at school, and all school-aged children of diverse ethnic and socio-economic groups are reached $[8,9]$. Recognising the social determinants of health and that health involves more than the absence of disease, interventions that address the school environment have been suggested to be more effective than single component strategies in changing health behaviour and promoting well-being [2]. Reviews describe effects of interventions of combining diet, physical activity, and well-being, using complex multicomponent interventions [10,11,12].

One approach is the WHO's Health Promoting Schools framework (HPS) [13,14], which has been widely operationalised and used within the European context [1518]. Langford et al. [19] highlight changes in at least three areas of school life: 1) Formal health education 2) Ethos and environment of the school and 3) Engagement with families or communities or both. Thus, the HPS model stresses the importance of complementing health education with a supportive school ethos and environment, together with a high level of engagement from the family [20]. Within the framework of the HPS approach that supports democratic and inclusive structures and social relations, children's genuine participation has been found to promote children's action competencies in health [21,22,23,24] and health behaviour [24]. To support this, health education should build upon a democratic approach [25]. In a systematic review, students' participation in school health promotion programmes has been found to impact positively on the students themselves, the school as an organisation, and interactions and social relations at school [26].

Many Danish children bring a packed lunch from home every day [5]. Therefore, the food children eat at school is highly influenced by parental choices. Some studies have shown difficulties in implementation of components targeting the parents, as their engagement is low thus making it challenging to involve the parents [27].

Health promoting interventions hold challenges when added to the schools existing agenda as an extra burden, and it has therefore been argued that school health promotion initiatives should build into the school's curricula, so that they are perceived as "add-ins" by schools, teachers, and school children rather than "add-ons" [28]. This aspect may be important for the willingness of schools and teachers to participate and thus to the implementation and success of the intervention.

Research has shown that complex and multicomponent interventions are seldom implemented as planned [29,30]. Modifications and deviations are important to identify in understanding overall results [31]. Therefore, thorough process evaluation, including detailed monitoring of the implementation is essential [27].

Based on the HPS approach and the paradigm of democratic health education, the school health promotion intervention We Act - Together for health (We Act) was developed. As We Act, is a multicomponent intervention, requiring a detailed description of the study protocol and evaluation methods, the aim of this paper is to describe the theoretical frame for the project, the development of the We Act intervention, and the design of the efficacy study, including the methods used for the scientific measurements, and the pilot study.

\section{Methods and Materials}

\subsection{The "We Act - Together for health" Intervention}

The objective of the We Act - Together for Health intervention is to promote pupil's dietary habits, physical activity level, school-well-being and social capital, through children's active participation, developing their action competence, and promoting a healthy school environment. Also by improving the dietary quality of the packed lunches and between meal-snacks brought from home through parental involvement. The target groups are children in $5^{\text {th }}$ and $6^{\text {th }}$ grade, their teachers, parents and school management.

Theoretically, We Act - Together for Health is inspired by the Health Promoting School (HPS) approach [14], Democratic Health Education, and the health educational method; the IVAC (Investigation Vision Action Change) approach [25,32]. The program theory and causal assumptions for We Act are that school children's' participation in health education following the IVAC model develops their action competence in health and this, along with support from teachers, school management and parents, initiates a change process creating a healthy supportive school environment, leading to an increase in nutrition quality and dietary intake, physical activity, social capital and well-being in school children (Figure 1).

The three core principles of the We Act program are 1) children's participation in health education following IVAC, which states that children can act as health promoting agents when being actively involved in the process, 2) a holistic concept of health, and 3) health education in the classroom must be supplemented by change processes at the school level and in the family to create health promoting environments.

\subsubsection{The Educational Component}

This component comprises four health educational programs that are integrated into the curriculum through language (Danish), maths and science, and developed to fulfil national educational objectives of these subjects, as well as health educational objectives for grades 5-6. Health education is a mandatory topic according to the Danish Educational Curriculum that must be integrated into existing subjects. The programs have a holistic concept of health and follow the IVAC model with emphasis on pupils' genuine participation and development of action competence.

\section{IEAT and IMOVE (IVAC - Investigation phase)}

The first step of the IVAC model was the Investigation phase. Teacher guides and pupil assignments were developed. This phase comprises the IEAT and IMOVE programmes

The IEAT and IMOVE programmes started with a week where the children had to investigate their individual food and meals, and physical activity habits in the school through a mapping of their daily practices. The school children collected data on food, meals and physical activity for one week to cover any variation. In the 
following week(s) the children used their data when working individually and in smaller groups with different assignments and had class discussions with teachers concerning broader societal determinants.

IEAT: The purpose of IEAT was for school children to gain knowledge, skills, and attitudes to food, meals, and health to enable them to make informed choices that could promote their health and the health of others, while promoting a supportive environment within the class. Furthermore, the aim of the IEAT programme was for each child to create a handout "My food and meals in the school" to take home and discuss with their parents, the handout included different overall messages on how to create a healthy lunch and between meal snacks for the children. IEAT integrated health education and food into the formal school curriculum in the subjects Danish and science.

To collect data on their food and meal habits, the school children filled out a log-book in which they reported what they had been eating. This was done by writing the contents of their packed lunches and in between meal snacks on a plate model, and by answering a few questions regarding their food and meal experiences (where did you eat, who did you eat with, what did you think about the meal experience altogether). In the following weeks, the children carried out different assignments both individually and in groups where the data they collected was used. Furthermore, tasks showing how a healthy packed lunch could meet the official dietary guidelines were included, along with reading assignments and video clips which lead to discussions on social and cultural aspects of food and meals.

IMOVE: IMOVE aimed to gain knowledge, skills, and attitudes toward physical activity and to develop the children's insight into how to integrate physical activity into their daily life practices. IMOVE integrated health education and physical activity into the formal curriculum and was carried out in the maths classes.

To gain insight into their level of physical activity during the school day, the school children wore a pedometer during school hours for one week. At the end of the school day they recorded their steps taken. Afterwards, the school children used the data in assignments, and the teacher facilitated health discussions in the class. The children calculated averages and differences among weekdays, between boys and girls. Furthermore, they compared their step data with the recommendations for daily steps for children and with data from school children from Kenya.

Vision workshop (IVAC - Vision phase)

After the school children had completed the IEAT and IMOVE activities their knowledge of food, meals and physical activity and the factors and situations influencing their health habits was increased. At this point, a vision workshop was conducted. The purpose of the vision workshop was to improve the school children's engagement by developing, sharing and discussing visions on how they could support their health and the health of others, and also by discussing ways in which the school environment could support their health. The vision workshop was facilitated in steps through a democratic process. The teacher started by introducing the children to the concept of visions and that all ideas were welcome. Brainstorming in the class, anonymous voting where the most popular visions were chosen and worked upon further in smaller groups. The teacher formed groups based on the pupil's $1^{\text {st }}$ and $2^{\text {nd }}$ prioritization. Hereafter pupils worked in their groups with their visions concretising these using creative methods and a pre-printed poster which illustrated motives, barriers, how the visions could be supported and by whom. The vision workshop ended with the school children presenting their visions at a dialogue meeting where the parallel class or other classes, the school nurse, the school management and the parents were invited.

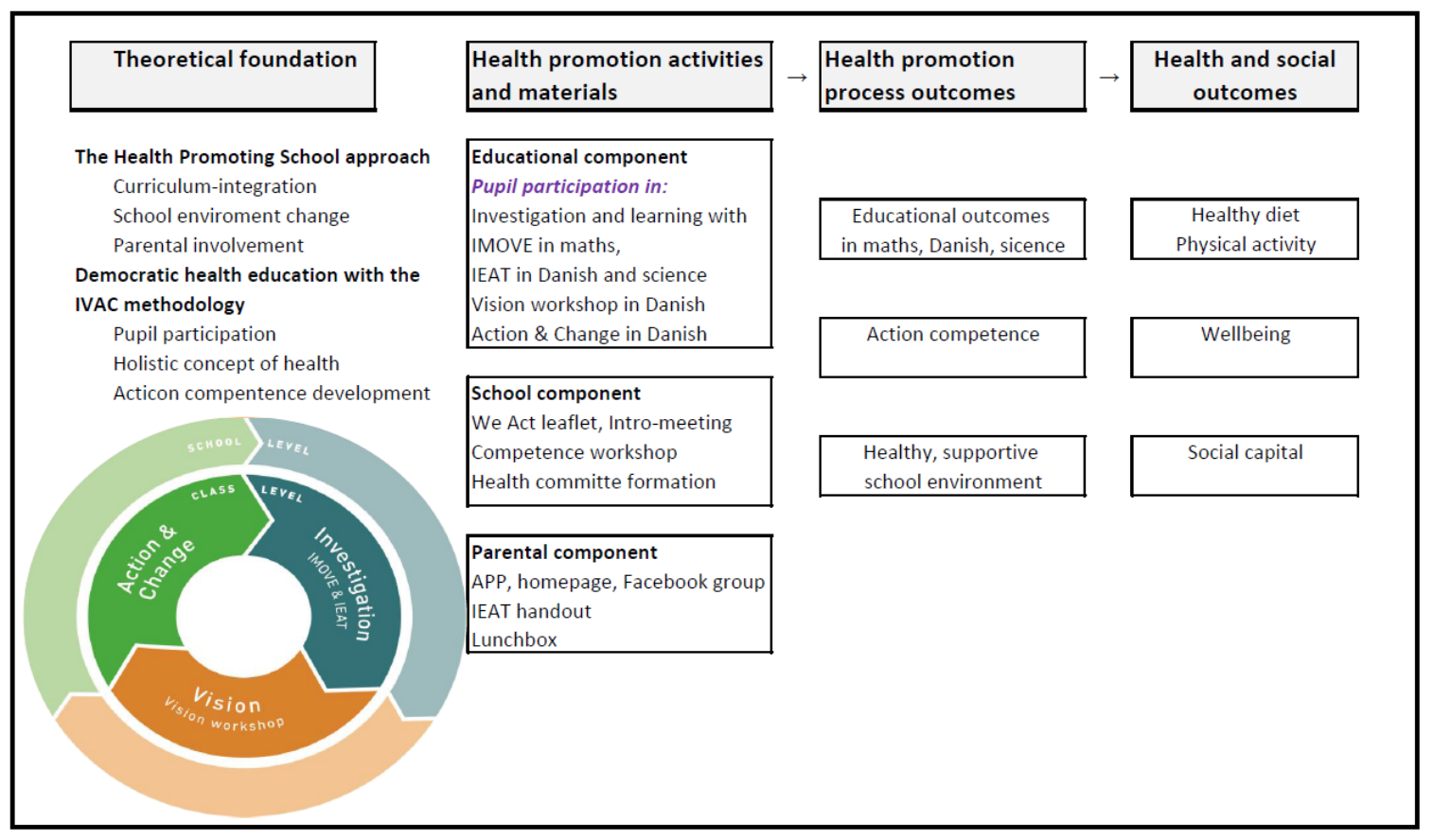

Figure 1. Intervention theory for We Act - Together for health, a health promotion school intervention

The intervention theory and causal assumptions for We Act were that pupils' participation in health education following the IVAC model would develop their action competence in health and social competence, which, along with support from teachers, school management and parents, would initiate a change process towards a healthy supportive school environment, leading to healthy diet, physical activity, well-being and social capital among pupils. 
Action \& Change process (IVAC - Action \& Change phase)

In the period after the vision workshop the school children continued to work with different action plans based on some of their visions. Their work could be continued in the classes relevant to the topic. Some examples are; Danish, home economics, history or as part of the newly introduced supportive education, which are extra lessons placed at the end of the school day where teachers and pedagogical personnel are free to carry out various activities. The purpose of this phase was to give the children some concrete experiences with (collective) actions related to their vision in the classroom, outside the classroom and possibly also in the family or community. The children were the drivers of the process and the teacher facilitated the process while the school management supported the process.

The educational material developed to guide and support the process includes teacher's guides for IMOVE, IEAT, and Vision, Action \& Change, pupil assignments for IMOVE and IEAT, step data sheet, food diary, poster templates and worksheets for group work. The teacher's guides indicate the procedures for each lesson. IMOVE was developed and evaluated earlier with respect to its potential to foster participation and enhances reflection concerning physical activity [33,34]. The material is available in English on the IMOVE website [35].

\subsubsection{School Component}

\section{Leaflet}

Initially, a "We Act - Together for health" leaflet describing the intervention was distributed to the schools; the leaflet described the theoretical background, timeframe, main objectives/learning goals of the integrated curriculum materials was developed targeted the school staff. The leaflet also described the "add-ins" of the intervention, e.g.: Integrated curriculum materials, support to the integration of physical activity in the school day, the potential to achieve better results due to healthier children, increased interdisciplinarity, and support for a health promoting school environment. The leaflet had two aims; to be informative and to create awareness of the project.

Introductory meeting

The purpose of an introductory meeting with teachers or teaching representatives, who were invited along with a representative of the school management and a person from the health staff, was to set the scene for the intervention and to start the process of setting up a health committee.

\section{Competence session}

The purpose of the competence session was to provide the teachers with knowledge and exchange experiences of how to create a health promoting school in terms of healthy eating, physical activity, and well-being. The focus was on democratic health educational processes holistic health concept and active involvement of school children, the IVAC approach and introduction of the educational materials. All the involved teachers were invited along with the school management and health staff.

Health committee

The purpose was to set up a school working group/health committee composed of people from the school management, teachers, health staff and if possible, other resource persons that may support the action and change process. The aim of this committee was primarily to support the work on the visions which have perspective at the school level and thus to support the creation of a health promoting school environment. Ideally, the health committee should do their own investigation - in the first phase (investigation phase) - on current school health practices in general, while focusing on food and meals and physical activity. In the vision phase, the health committee participated in the dialogue meetings where the children shared their visions, and worked with both the school children's visions as well as their own visions at the school level. Their role in the action and change phase was to follow and if necessary support or facilitate the process depending on the content of the pupils' visions and action plans. This process could - if the school finds it attractive - result in a written policy.

\subsubsection{The Parental Component}

\section{Healthy Kids Denmark APP $\subset$}

The parents could download an APP developed for this project from android and iOS platforms. The app contained topics of inspiration for the packed lunch, every day practices regarding packed lunches, dietary guidelines in general, and regarding packed lunches, a quiz, some videos for inspiration on different types of packed lunches, and videos illustrating different perspectives of children in the target group on packed lunches (good and bad packed lunches). It was also possible for the parents to share ideas and save other people's ideas as favourites.

Hand out - "My food and meals in the school"

The parents received a handout "My food and meals in the school”, which they could discuss at home with their child. The children worked on a pre-printed version of the handout, which they personalised at school with relevant messages regarding food and meals, from their own point of view. The handout contained messages on food and nutrition but also on the eating environment and the meal advice created by the class.

\section{Homework}

The IEAT teaching material included homework assignments, creating opportunities for the children to discuss food and meals with their parents, e.g. tasks regarding the dietary guidelines (illustrated in the Healthy Kids APP), dietary habits in the family and factors influencing the family diet.

\section{Facebook group}

The purpose of the Facebook group was to create a platform where the parents could gain inspiration for packed lunches and between meal snacks for their children, to share experiences and discuss aspects of packed lunches and between meal snacks. A written message was sent twice to the parents of the involved children about the possibility of sending a request to join the group. Parents received information about the Facebook group in the introductory information and in the handout the children made for their parents.

\section{Homepage}

A homepage was used for communication and dissemination of relevant information about the project, the primary target group was the parents, but other groups such as the teachers and school children could also use the homepage. Each school had login information to ensure that the intervention schools and control schools received 
only information relevant to them during the intervention period.

\section{Lunch boxes}

All the participating school children received a lunch box, containing different divisions that could make a separate space for more fruit and vegetables. The box was also intended to increase awareness of the intervention in the home setting.

\subsection{Study Design}

The original planned study design was a cluster randomised controlled intervention study. Due to difficulties in recruiting enough schools for the main study, it was decided to change the design into a quasi-experimental controlled pre- and post-intervention study.

Inclusion criteria for each school were that the school did not have a school food programme, there was a sufficient number of children in $5^{\text {th }}$ and $6^{\text {th }}$ grade and the motivation of the school to participate.

\subsection{Recruitment of Schools}

Municipalities in Copenhagen region and Region Zealand were contacted. The municipalities were introduced to the project, the overall idea and the aim of the intervention. Afterwards, recruitment material was sent to the municipality with further details on the intervention and required time resources for the involved schools and teachers. Contact was established with 27 municipalities. Fifteen municipalities disseminated the information directly to the schools, 3 municipalities did not want to disturb their schools with further projects, and in 9 municipalities they wanted the research group to contact the schools directly and send the recruitment material. Afterward, the municipality or single school returned with their answer. In total 210 schools were contacted.

Four schools from four municipalities replied to the request and signed up for the project. The four intervention schools were matched afterward with four control schools. The control schools were selected among schools in the same municipality. The rationale for using this approach was to make intervention and control schools as comparable as possible, as schools within the same municipality are often exposed to the same local health policies and political standpoints. Furthermore, the control schools were matched with the intervention schools by assessing the families' social backgrounds (assessed by a central person from within the municipality responsible for the school area) and the size of the school (number of children). A flowchart mapping the various stages of recruitment is shown in Figure 2. There were several reasons as to why the schools refused to participate: time pressure because of the implementation of a new school reform in Denmark, already focusing on health, another focus than health, insufficient time, the teachers were not interested as the teaching for the next year had already been planned.

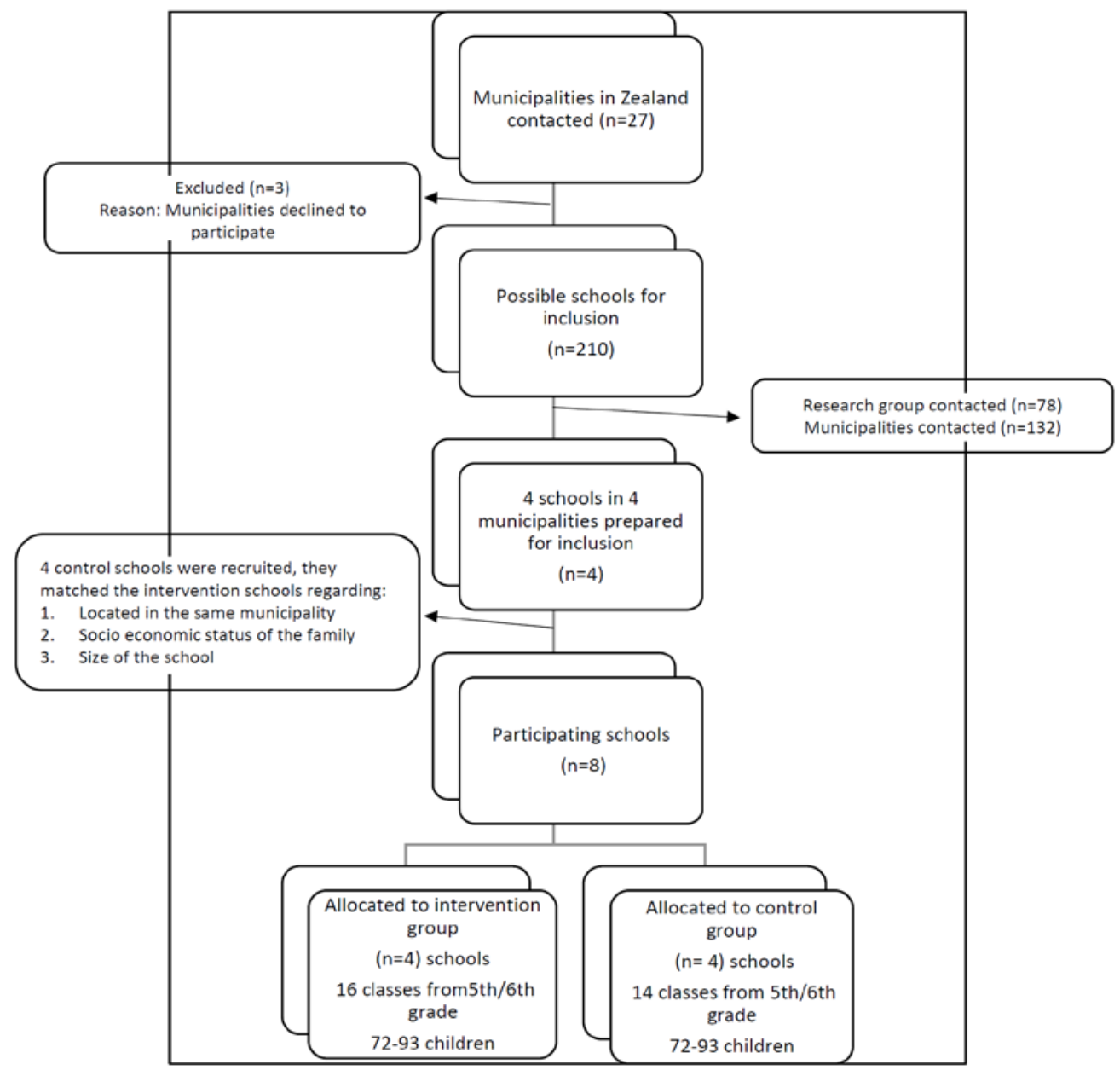

Figure 2. Flowchart of recruitment stages, number of municipalities, schools, classes and school children 
The recruitment procedure resulted in clusters going from 72-93. Children from 30 school classes $\left(5^{\text {th }}\right.$ and $6^{\text {th }}$ grades) at eight Danish schools were invited to participate in the study. At baseline, a total of 656 school children were included.

\subsection{Ethical Issues}

The We Act Study adheres to Danish ethical standards and has been approved by the Danish Data Protection Agency, $18^{\text {th }}$ April 2015, ref: 2015-41-4201 and reported to the regional ethics committee for the Capital Region of Denmark, Protocol no.: H-7-2015-FSP1. They concluded that formal ethics approval was not required because no human biological material was collected.

When schools were invited to participate, written information targeting the school leader and the teachers was sent to all schools explaining the implications of participation. Teachers, children and their parents at the participating schools were informed that participation was voluntary, that their information would be used for research purposes only and treated confidentially and of the possibility of withdrawing during any stage of the study. Parents were informed of the study and the possibility to withdraw their child from the study by written information on the parental e-platform which is used daily by parents, and school as means of communication, indicating the purpose of the study, the implication for and involvement of their child. If the parents had further questions, they could call the project manager.

\subsection{The "We Act - Together for health" Intervention Study}

The "We-Act" intervention was implemented from November 2015 to May 2016. The study measurements were collected at baseline in Oct-Nov 2015 and at followup in May-Jun 2016. A qualitative follow-up was conducted one year after baseline. In the intervention period, a process evaluation was conducted alongside data for the qualitative case study (Figure 3). Data from the intervention school were collected at the same time as data from the matching control school and collected successively at the four paired, intervention and control schools. Baseline data were collected just before the intervention period began. The data collection on diet and physical activity was conducted over five consecutive days. A whole school week was chosen to cover the variability of the lunches and between meal snacks, and the variability in physical activity. The period of the five consecutive days ensures almost the same number of scheduled lessons and subjects on the measuring days among the children at the intervention and control schools. Data on well-being, height, and weight were collected on one day in each of the measurement periods. Instruction on how to perform the data measurements were given to the school children on the first day, in the first lesson in the classrooms, in each of the participating classes. The research staff attended a training session on the use and procedures for the scientific measurements before the data was collected.

\subsubsection{Measurements}

\section{Dietary assessment}

The school children's dietary intake was determined using a digital photographic method (DPM) during the whole school day over five days in the two measurement periods. The DPM was developed and validated earlier [36]. In this study, further development of a software program and connection of scales, a scanner, and a camera to the computer optimised the method, so the weight for the whole meal, and the vegetables and the fruits were collected automatically.

The meals were photographed automatically using a webcamera (Logitech Webcam HD C930e) mounted on a tripod with the lens 0.37 metres above the meal and with a camera angle of approximately $45^{\circ}$ - a procedure that allows visibility of the foods in three dimensions in the digital image. To standardise the digital images, a placemat $(0.4 \times 0.4 \mathrm{~m})$ with markings for placement of the plate were fixed to the scales. The placemat was divided into squares of $2 \times 2 \mathrm{~cm}$ to support the estimation of the size of the different food items. When the children had something to eat, often in the break around ten o'clock and again at lunch, they placed their meal on a plate, which was distributed to them. At the beginning of the break all the meals were photographed individually and at the end of the break, the plates were again photographed this time with or without leftovers. If a child had a sandwich, the sandwich was photographed closed and then the child was asked to open the sandwich to photograph the content. Also, the participants were asked questions about specific food items if the research staff assessed that it would be difficult to see them in the digital image.

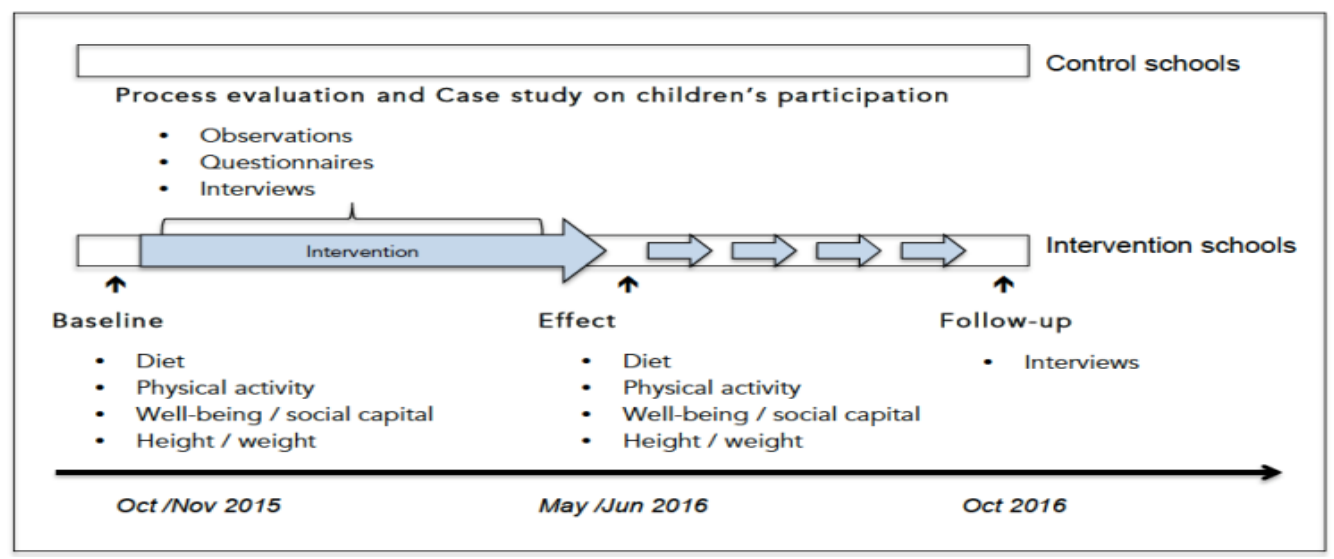

Figure 3. Study design 


\section{Physical activity}

The school children's physical activity was determined using pedometers during the school day. The first day the school children were instructed on how to wear the pedometer. They were told not to shake or tamper with the pedometer and to go about their normal activities during the school days when they were being monitored. In the morning when the school children arrived at the school, up to ten minutes before the first lesson started, the pedometers were handed out and then collected again right after the last lesson of the day. The pedometers were worn for the whole school day, also in the physical education class. The pedometers were sealed. We used the pedometer Yamax-Digiwalker SW-200, and performed shake tests [37] before use.

\section{Well-being and social capital}

Data on well-being, social capital, action competence and background data were assessed by an electronic questionnaire conducted in Limesurvey (on-line questionnaire frame). The majority of questions were derived from the 2014 Danish Health Behaviour in School Children survey (HBSC), and 6 self-constructed questions were added. Background data included age, migration status, and class-level, as well as the socioeconomic background of the child's family. To assess the latter, The Danish Occupational Social Class (DOSC) measure was used [38]. We selected nine questions from the HBSC Survey reflecting child cognitive social capital in the school setting. We selected nine questions reflecting three latent variables representing the following three subscales: horizontal social capital (3 items), vertical social capital (3 items) and sense of belonging (3 items). These were derived reflecting both the theoretical construct and previous empirical operationalisation of child perceived social capital in the school setting for children age 10-12 $[39,40]$.

\section{Anthropometrics}

The height and weight of the school children were measured. The measurements were taken in light clothing and without shoes. Weight was measured to the nearest $0.1 \mathrm{~kg}$ using Soehnle Verona 63749 digital person scales, and height was registered to the nearest $1.0 \mathrm{~cm}$ using a Soehnle 5003 digital height rod.

\section{Process evaluation}

The purpose of the process evaluation was to evaluate the implementation fidelity in the We Act intervention by examining how each component was delivered in practice and identify adaptions. The key features from the recent guidance of the Medical Research Council for process evaluation of complex interventions were used as a framework [41] and operationalised into the following research question: Was the target audience reached with the proposed dose of lessons, materials and activities, and the intended quality of delivery according to the core concepts of the intervention?

The process evaluation applied a mixed methods design [42], and data were collected concurrently and evenly at the four schools during the implementation period by field visits, classroom observations, questionnaires to teachers to be distributed when each of the educational programs were delivered. By the end of the implementation period, questionnaires to parents were distributed and interviews were conducted with the key teachers and principals from each school. Furthermore, in the next school term, a follow up interview was conducted in each school. The data collected were analysed separately and used triangulation.

Qualitative case study on pupils' participation in relation to social capital generation

The qualitative case study aimed to get a deeper understanding of mechanisms and contextual forces driving social capital generation in the school setting, focusing on pupil participation and structural changes at the school level. Drawing on We Act as a case on pupil participation in health promoting activities, and the HPS approach, the study applies qualitative multiple case study analysis, focusing on two cases that differ with respect to socioeconomic school characteristics to look for similarities across cases. Qualitative data including focus group interviews with children, interviews with teachers and school principals, participatory observations, and pupil material are triangulated with respect to each case followed by a cross case analysis where data from the two cases are synthesised.

\subsubsection{Pilot testing}

The intervention components, scientific measurements, and survey were tested before use in the main study. The pilot testing was conducted in collaboration with one Danish Public school, and a participatory $5^{\text {th }}$ grade class with 22 school children and two teachers. The pilot study ran from May 2015 to October 2015.

Developing and testing the intervention components

The IMOVE program was developed and tested earlier and found to be suitable to promote learning on physical activity integrated into maths [33-35, 43].

IEAT was developed with inspiration from IMOVE, building on the same principle of school children's participation in reporting/measuring a daily practice - in this case, the lunch meal and between meal snacks. IMOVE was carried out at the pilot school along with the testing of IEAT, the vision workshop and the Action and Change process. Afterward, the participating teachers were interviewed, and the educational material and process were evaluated in three focus group interviews involving the school children. Observation of the implementation of the intervention at class level (IMOVE, IEAT, vision workshop and action and change phase) was also used in the pilot study. Moreover, researchers assisted the process in collaboration with teachers. Corrections were then made to IEAT, the vision workshop and with respect to the school children and teachers understanding of the overall project, according to the findings.

The introduction meeting was tested with the teachers, school management, and school, at the pilot school along with the setup of a health committee in the school regime. The competency session targeting the school level was tested in an internal group. The original school level component was not tested in collaboration with the pilot school as intended because the pilot school declined to participate, due to time constraints and lack of resources. As a result of the pilot study and reluctance in the recruitment process of schools to participate in a more extensive school health policy process, the school level component was reduced to include the establishment of a health committee that had to meet, and coordinate with the researchers and support the school children's process. 
Before the development of the family level components, explorative research was carried out. Dietary guidelines for packed lunches for children aged 10-12 years were developed. Ten qualitative interviews were conducted, five with children in the age range 8-12 years and five interviews with parents who had children in the same age range as the target group. The focus of the interviews was to explore the everyday practices in relation to packed lunches. By whom, when and how are the packed lunches created? What are the challenges, which barriers and motives do the target groups perceive relating to planning, creating, and eating the packed lunches brought from home? The knowledge gathered from the interviews was used in the communication with the parents. The considerations behind the democratic paradigm of health education were also used in the communication with the parents. The programme components targeting the parents were tested in different ways. A beta version of the Healthy Kids application was tested. Five parents (four women and one man) and two experts tested the application and participated afterward in an interview. Based on this evaluation the Healthy Kids app was developed further, the text was shortened and more pictures were put into the Healthy Kids app.

After considerable research on lunch boxes and lunch bags, and testing various appearances on children in the same age group as the target group, it was decided to go with the one the children liked the most which was also the one with room for fruit and vegetables and between meal snacks.

After the pilot testing was completed the material and different approaches were adjusted and developed to improve and qualify the intervention for the main study.

Pilot and feasibility test of the research measurements, survey and process evaluation

The introduction to the scientific measurements was tested at the pilot school.

The optimised and automated version of the DPM, including the procedure for data collection of dietary intake during the school day was feasibility tested at the pilot school before the baseline measurements were taken. The procedure for collecting data on physical activity, the electronic questionnaire and the measurements of height and weight were tested at the pilot school as well. A focus group discussion with six school children was conducted to evaluate the questions from the electronic questionnaire. Minor adjustments were made before the main study was carried out.

First versions of guides for observations, interviews, and questionnaires for the process evaluation were developed and tested during the pilot study.

\subsubsection{Statistical Analyses}

\section{Power calculation}

Sample size calculations were based on $80 \%$ power and $95 \%$ confidence. They aimed at a difference of $20 \%$ of fruit and vegetable intake during the school day, estimating the intra-class correlation to be 0.01 , based on data from the EU funded study 'Pro Children Study' [44] and used in the Boost-study [45]. Regarding physical activity, an increase of $15 \%$ in the number of steps should be detected using an intra-class correlation to be 0.05 , as in other studies $[46,47]$. For this difference in fruit and vegetable intake and physical activity to be detected at a minimum, a total of four intervention and four control schools with 75 children in each group was required.

Planned statistical effect analyses

The primary outcomes were dietary intake, physical activity, well-being and social capital. The effect on dietary behaviour was measured as changes in intake of fruit and vegetable during school time. Separate analysis for fruit and vegetables were planned. Furthermore, analyses on dietary components are also planned; changes in total bread and wholegrain bread, total pasta/rice and wholegrain pasta/rice, total meat and quality of meat (red/white and fat $(>10 \mathrm{~g} / 100 \mathrm{~g}) /$ non-fat $(<10 \mathrm{~g} / 100 \mathrm{~g})$, total fish and lean/fatty fish, and total snack products. The effect of the We Act intervention on the children's dietary intake on food groups will be analysed by comparing the change in mean daily intake over a school week of the children in the interventions group to the children in the control group, adjusting for the baseline values. To account for the cluster-design and repeated measurements, changes from baseline to the effect measurement were analysed by a multilevel multivariate regression analyses.

The effect on physical activity was measured as changes in number of steps during school time analysed by comparing the change in mean daily steps during the school hours over a school week of the children participating in the We Act intervention to the change of the children in the control group, adjusting for the baseline values. A multilevel multivariate regression analysis was conducted for this continuous outcome.

The last primary outcome is social capital. Nine questions were selected to consist of 3 latent variables representing the following three indexes: horizontal social capital, vertical social capital and sense of belonging. To measure the internal consistency of the indexes the coefficient of reliability - Cronbach Alpha values were calculated for each index. To make an easy interpretation while recognising the ordinal nature of the response categories, the three indexes were constructed based on number of times a respondent had answered "agree" or “strongly agree.” Hence, each item was assigned either 1 or 0 points. One point was given if the responder answered "agree" or "strongly agree" and 0 points were given for negative or neutral responses. The three indexes thus gave each responder $0-3$ points. Hereafter the three indexes were categorised into 'high' $=3$, 'moderate' $=2$ and 'low' $=0$ or 1 . The effect of We Act on the children's social capital is analysed by comparing the children in the interventions group with children in the control group in these measures reflecting social capital, adjusting for the baseline values and individualistic confounders using multilevel ordinal logistic regression analysis.

\section{Discussion}

The justification for initiating a school-based complex multicomponent intervention study was the need for increased focus on children's health behaviour regarding nutrition, physical activity and well-being, and that the school is a prime setting for health promotion. The HPS approach, democratic health education paradigm and the IVAC model were identified as a robust theoretical 
framework. Also, the need for designing, testing, and evaluating multicomponent interventions was introduced, which target curriculum, school environment, and families, as recent research suggests that these types of interventions can be more effective. Furthermore, it was argued that participation was a key element.

Both the intervention components as well as the scientific measurements were tested before the main study and were adjusted accordingly before the implementation of the intervention.

Identifying enough schools to participate in this intervention was challenging. Schools are generally inundated with requests to join research projects and plan the school year well ahead. Therefore, it is an advantage to plan the intervention well in advance when dealing with the school regime. The timing of the intervention was also a barrier to recruitment as it coincided with a new school reform which all schools in Denmark were busy implementing.

A quasi-experimental design was conducted; thus, the matching of intervention and control schools was of high importance. The randomisation procedure was a limitation of this study, because a complete randomisation was not possible due to the reluctance of the schools to participate in a complete HPS approach. However, the intervention schools were matched with controls on key variables. All schools had to live up to the inclusion criteria, and the number of schools and school children required was also considered to give enough power to the study. The procedure of collection of the scientific measurements was standardised. The measurements were done in the same week at both the intervention and control schools to minimize the influence of the external environment.

The methods used for assessment of diet and physical activity were planned to have a minimal burden on the participants. Assessing dietary intake among children is especially challenging $[48,49]$. Using a validated digital photographic method overcomes the recall problems and difficulties in estimating portion sizes that exist when collecting dietary data on children [49]. The selected methods secure high response rates among the school children.

The intervention builds upon a theoretical framework including the Health Promoting School approach, Democratic Health Education, and the IVAC-model. In a review Diep, et al. [50] show that school interventions based on a solid theoretical framework were more effective according to dietary behaviour. In contrast to the Moralistic approach, this intervention builds upon a Democratic Health Education approach. According to Jensen [25] these are two conflicting paradigms in health education. Moralistic health education lacks involvement of the school children's own opinions of what a healthy life is for them, focuses merely on pre-determined behaviour changes, drawing on a disease-oriented, closed health concept and is limited to health education in the classroom without consideration of involving the school environment. On the other hand, a Democratic Health Education approach is based on teaching the school children to actively consider their own views and critically incorporate them into what they learn in class. It is based on a broad and positive concept of health, and the importance of considering how health education in the classroom can be supplemented by changes in the school environment. School children learn to develop their own abilities so they can act at both a personal level and a societal level, thus increasing their action competences.

Lack of institutional support has shown to be a barrier to implementation [27]. The We Act intervention tries to meet this barrier by directly and indirectly reinforcing the school level component, e.g., the leaflet to the school staff, the introduction meetings and the competence session targeting the teachers and the school management. Furthermore, it was recommended that the schools set up a health committee. The committee may be an important link to the implementation of the school children's visions, and support them in taking actions or smaller steps towards their visions, even when these seem to be unrealistic thus gaining experience with the democratic decision-making processes. It is crucial that the school move on with the visions and incorporates them into the school environment for the children to learn from the Democratic Health approach. Another critical factor is that the school management back up the teachers work, and that the teachers and school management support the school children in their visions. This is considered in the intervention components targeting the school, e.g., the competence session.

The setting up of a health committee in the school was tested in the pilot school before the intervention. This proved to be a significant commitment for the school and the partners in the health committee which complicated the process. There were various reasons for this, such as the recent introduction of a school reform, the different focus on health for the various partners and the time commitment required to set up the committee.

The evidence for the impact of the involvement of family is inconclusive. In a review Langford et al. [27] describe that studies consistently identified engaging families as the most challenging and least successful intervention element, despite being one of the three domains in the HPS approach. The engagement is low, and it is difficult to involve the parents. According to Eather et al. parents are difficult to engage, and many students were not supported at home in completing their intervention's home-based activities [51]. It may be that current approaches to parental involvement are inadequate and more innovative methods are required. In the We Act study explorative research was carried out before development of the family component, to consider the broader aspects of preparing the packed lunches and between meal snacks to increase the relevance but also to incorporate the holistic health perspective. The intervention components targeting the parents were many, and different channels were used for the purpose of reaching the parents in different ways. Furthermore, the components linked to the other components, e.g., the homework referred to the Healthy Kids app, in the app-images were used of the lunch box which had been provided, and in the information letters there was a link to the homepage.

Evaluation of the health promotion initiatives is of high importance. Intervention components are not always implemented as intended. Low fidelity and small doses delivered challenged the validity of the assessment of the effectiveness of multi-component interventions [30]. Therefore, thorough process evaluation, including detailed 
monitoring of the implementation is essential [27,30]. Process evaluations can suggest explanations, helping to identify what works, for whom, in what contexts and why. There seems to be a lack of reporting reach, dose, fidelity and acceptability of these internally effective interventions which limit their external applicability within different contexts. A review of school based intervention studies reporting process evaluation data showed a considerable variation in fidelity across trials [27]. More information about external validity could enable future studies to gain insight into best practice regarding health promotion initiatives in schools. In the We Act intervention, a thorough process evaluation based on multiple methods and data sources was included. The process evaluation contributes to a varied picture of the intervention components, the implementation, fidelity, and acceptability in the different target groups.

\subsection{Implication for Practice}

The We Act intervention study will provide new knowledge on the implementation and effectiveness of a multicomponent school based intervention targeting school children, teachers, school management and parents to improve dietary habits, physical activity, and wellbeing among school children.

The We Act intervention is planned to become a sustainable initiative. This process is supported by the IVAC approach which is a circular process, encouraging the schools (at the introductory meetings and competence sessions with the teachers and school management) to see the actions initiated in the intervention as potentials for becoming sustainable and being integrated within their school regimes. Thus, the process starts in the $5^{\text {th }}$ and $6^{\text {th }}$ grades and the next year another group of school children in the new $5^{\text {th }}$ and $6^{\text {th }}$ grades who are going through the process investigate, make visions and go through the action phase and finally end up with an evaluation of the changes. The qualitative follow-up will examine to which degree the We Act intervention is sustainable.

An important part of the evaluation will be, to sum up the various intervention components to inform stakeholders and health plan administrators.

\section{Acknowledgements}

The authors would like to thank all participating schools, schoolchildren, parents, teachers, school management and other participants on the health committee for their time and involvement. We would also like to thank the Advisory Board for their dedication and involvement in the project and Professor emeritus Bjørn Holstein and associate professor Mette Rasmussen from the Danish National Institute of Public Health for guidance regarding the HBSC questionnaire.

\section{Competing Interests}

The authors declare that they have no competing interests.

\section{Funding}

This study was funded by, Nestlé Denmark, the Technical University of Denmark and Steno Diabetes Center Copenhagen. Ph.D. scholarship for Nanna Wurr Stjernqvist was co-financed by Steno Diabetes Center Copenhagen and the Technical University of Denmark. The funders had no role in the design, data collection, analysis, and interpretation of data.

\section{List of abbreviations}

HPS: Health promoting school

IVAC: Investigation Vision Action Change

DPM: Digital photographic method

HBSC: Health Behaviour in School-aged Children

\section{Declarations}

Ethics approval and consent to participate

See Ethical issues on page 12.

\section{Consent for Publication}

Not applicable.

\section{Availability of Data and Material}

Examples of the teaching materials used in the study can be found on the websites for IMOVE [35], and We Act -Together on Health, IEAT. We Act zone is only in Danish. [52].

Data are available from the corresponding author: Marianne S. Sabinsky, Division for Diet, Disease Prevention and Toxicology, National Food Institute, Technical University of Denmark.

\section{References}

[1] Lytle, L.A., and Kubik, M.Y., "Nutritional issues for adolescents", BEST Pract Res Clin Endocrinol Metab, 17(2). 177-89. 2003.

[2] Patton, G.C., Sawyer, S.M., Santelli, J.S., Ross, D.A., Afifi, R., Allen, N.B., et al. "Our future: a Lancet commission on adolescent health and well-being", Lancet (London, England), 387 (10036). 2423-78. 2016.

[3] Whitaker, R.C., Wright, J.A., Pepe, M.S., Seidel, K.D., Dietz, W.H., "Predicting obesity in young adulthood from childhood and parental obesity", N Engl J Med, 337 (13). 869-73. 1997.

[4] Lytle, L.A., Seifert, S., Greenstein, J., McGovern, P., "How do children's eating patterns and food choices change over time? Results from a cohort study", Am J Heal Promot, 14 (4). 222-8. 2000.

[5] Petersen, A.N., Kildegaard, V., Rosenlund, M., Biltoft-Jensen, A., Hess, K. et al. Danskernes kostvaner (Dietary Habits in Denmark) Soeborg: Technical University of Denmark, National Food Institute. 2015.

[6] The Danish Veterinary and Food Administration , The Official Dietary Recommendations:Food, Meals \& Physical Activity [In Danish: Altomkost, mad, måltider og motion]. November 2017. http://altomkost.dk/deofficielleanbefalingertilensundlivsstil/deofficielle-kostraad/. Accessed $2^{\text {nd }}$. 
[7] Rasmussen, M., and Due, P., "Skolebørnsundersøgelsen 2010". København; 2011.

[8] Sancassiani, F., Pintus, E., Holte, A., Paulus, P., Moro, M.F., Cossu, G., et al. "Enhancing the Emotional and Social Skills of the Youth to Promote their Well-being and Positive Development: A Systematic Review of Universal School-based Randomized Controlled Trials", Clin Pract Epidemiol Ment Health, 11 (Suppl 1 M2). 21-40. 2015.

[9] Nielsen, L., Meilstrup, C., Nelausen, M.K., Koushede, V. Holstein, B.E., "Promotion of social and emotional competence", Health Educ, 115 (3/4). 339-56. 2015.

[10] Steward-Brown, S., What is the evidence on school health promotion in improving health or preventing disease and, specifically, what is the effectiveness of the health promoting schools approach? World Health. 1-26. March 2006.

[11] Brown, T., and Summerbell, C., "Systematic review of schoolbased interventions that focus on changing dietary intake and physical activity levels to prevent childhood obesity: an update to the obesity guidance produced by the National Institute for Health and Clinical Excellence", Obes Rev, 10 (1). 110-41. 2009.

[12] De Bourdeaudhuij, I., Van Cauwenberghe, E., Spittaels, H., Oppert, J.M., Rostami, C., Brug, J., et al. "School-based interventions promoting both physical activity and healthy eating in Europe: a systematic review within the HOPE project", Obes Rev, 12. 205-216. 2010.

[13] St. Leger, L.H., "The opportunities and effectivess of the health promoting primary school in improving child health: A review of the claims and evidence", Health Educ Res, 14 (1). 51-69. 1999.

[14] Young, I., "Health promotion in schools - a historical perspective", IUHPE - Promot Educ, 12. 112-7. 2005.

[15] Jensen, B.B., and Simovska, V., Models of health promoting schools in Europe, 2002.

[16] Lister-Sharp, D., Chapman, S., Stewart-Brown, S., Sowden, A., "Health promoting schools and health promotion in schools: Two systematic reviews", Health Technology Assessment, vol 3. 1999.

[17] Denman, S., "Health promoting schools in England - a way forward in development", J Public Health Med, 21 (2). 215-20. 1999.

[18] IUHPE. Achieving health promoting schools: guidelines for promoting health in schools Version 2 of the document formerly known as "Protocols and guidelines for Health pPomoting Schools.” 2008.

[19] Langford, R., Bonell, C.P., Jones, H.E., Pouliou, T., Murphy, S.M., Waters, E., et al. "The WHO Health Promoting School framework for improving the health and well-being of students and their academic achievement", Cochrane database Syst Rev, 4 (4). CD008958. 2014.

[20] Buijs, G., SHE strategic plan 2013-2016. 2013.

[21] Simovska, V., "Case Study of a Participatory Health-Promotion Intervention in School", Democr Educ, 20. 2012.

[22] Carlsson, M., and Simovska, V., "Exploring learning outcomes of school-based health promotion--a multiple case study", Health Educ Res, 27 (3). 437-47. 2012.

[23] Simovska, V., and Carlsson, M., "Health promoting changes with children as agents: findings from a multiple case study research", Health Educ, 112 (3). 292-304. 2012.

[24] Llargues, E., Franco, R., Recasens, A., Nadal, A., Vila, M., Pérez, M.J., et al. "Assessment of a school-based intervention in eating habits and physical activity in school children: the AVall study", $J$ Epidemiol Community Health, 65 (10). 896-901. 2011.

[25] Jensen, B.B., "A case of two paradigms within health education", Health Educ Res, 12 (4). 419-28. 1997.

[26] Griebler, U., Rojatz, D., Simovska, V., Forster, R., "Effects of student participation in school health promotion: a systematic review" Health Prom Int, 32. 195-206. 2017.

[27] Langford, R., Bonell, C., Jones, H., Campbell, R., "Obesity prevention and the Health promoting Schools framework: essential components and barriers to success" Int J Behav Nutr Phys Act, 12 (1).15. 2015.

[28] Schneller, M.B., Duncan, S., Schipperijn, J., Nielsen, G., Mygind, E., Bentsen, P., "Are children participating in a quasi-experimental education outside the classroom intervention more physically active?" BMC Public Health, 17. 1-13. 2017.

[29] Dusenbury, L., Brannigan, R., Falco, M., Hansen, W.B., "A review of research on fidelity of implementation: implications for drug abuse prevention in school settings", Health Education Research, 18 (2). 237-56. April 2003.

[30] Durlak, J.A., and Dupre, E.P., "Implementation Matters: A Review of Research on the Influence of Implementation on Program Outcomes and the Factors Affecting Implementation", Am J Community Psychol, 41. 327-350. 2008.

[31] Craig, P., Dieppe, P., Macintyre, S., Michie, S., Nazareth, I., Petticrew, M., "Developing and evaluating complex interventions: The new Medical Research Council guidance", Int J Nurs Stud, 50 (5). 587-92. 2013

[32] Simovska, V., "The changing meanings of participation in schoolbased health education and health promotion: the participants' voices", Health Educ Res, 22 (6). 864-78. 2007.

[33] Bruselius-Jensen, M.L., Bonde, A.H., Christensen, J.H., "Promoting Health Literacy in the classroom", Health Education Journal, 76 (2). 156-168. 2016.

[34] Bruselius-Jensen, M.L., Danielsen, D., Hansen, A.K., "Pedometers and participatory school-based health education - an exploratory study", Health Education, 114. 487-500. 2014.

[35] I MOVE -A teaching propgram for school children [In Danish: I MOVE -Et undervisningsprogram for skolelever]. http://imove.zone/. Accessed $2^{\text {nd }}$ November 2017.

[36] Sabinsky, M.S., Toft, U., Andersen, K.K., Tetens, I., "Validation of a digital photographic method for assessment of dietary quality of school lunch sandwiches brought from home", Food Nutr Res, 57 (20243). 2013

[37] Rowe, D.A., Mahar, M.T., Raedeke, T.D., Lore, J., "Measuring physical activity in children with pedometers: Reliability, reactivity, and replacement of missing data", Pediatr Exerc Sci, 16 (4). 343-354. 2004.

[38] Christensen, U., Krolner, R., Nilsson, C.J., Lyngbye, P.W., Hougaard, C.O., Nygaard, E., et al., "Addressing social inequality in aging by the Danish occupational social class measurement", $J$ Aging Health, 26 (1). 106-27. February 2014.

[39] De Clercq, B., Pfoertner, T.-K., Elgar, F.J., Hublet, A., Maes, L., "Social capital and adolescent smoking in schools and communities: a cross-classified multilevel analysis", Soc Sci Med 119. 81-7. October 2014.

[40] De Clercq, B., Abel, T., Moor, I., Elgar, F.J., Lievens, J., Sioen, I., et al.,"Social inequality in adolescents' healthy food intake: the interplay between economic, social and cultural capital", Eur J Public Health 27 (2). ckw236. 2016.

[41] Moore, G.F., Audrey, S., Barker, M., Bond, L., Bonell, C., Hardeman, W., et al., "Process evaluation of complex interventions: Medical Research Council guidance" BMJ, 350 (h1258). 1-7. 2015.

[42] Creswell, J.W., Research design: Qualitative, Quantitative and Mixed Methods Approaches. Second edition. Thousand Oaks. California. SAGE; 2003.

[43] Bonde, A.H., Bruselius-Jensen, M., "Is it feasible to use students' self-reported step data in a local school policy process?" Health Behaviour and Policy Review , 4 (6). 531-538. 2017.

[44] Klepp, K.I., Pereze-Rodrigo, C., De Bourdeaudhuij, I., Due, P., Elmadfa, I., Haraldsdottir, J., Konig, J., Sjostrom, M., Thorsdottir, I., Vaz de Almeida, M.D., Yngve, A., Brug, J., "Promoting fruit and vegetable consumption among European schoolchildren: rationale, conceptualization and design of the Pro Children project", Ann Nutr Metab, 49. 212-220. 2005.

[45] Krølner, R., Suldrup Jørgensen, T., Aarestrup, A.K., Christiansen, A.H., Christensen, A.M., Due, P., "The Boost study: design of a school- and community-based randomised trial to promote fruit and vegetable consumption among teenagers", BMC Public Health, 12 (1). 191. 2012.

[46] Murray, D.M., Catellier, D.J., Hannan, P.J., Margarita, S., Stevens, J., Schmitz, K.H., et al., "School-Level Intraclass Correlation for Physical Activity in Adolescent Girls", Med Sci Sports Exerc, 36 (5). 876-882. May 2004.

[47] Hjorth, M.F., Chaput, J., Michaelsen, K., Astrup, A., Tetens, I., Sjödin, A., "Seasonal variation in objectively measured physical activity , sedentary time , cardio-respiratory fitness and sleep duration among $8-11$ year-old Danish children: a repeatedmeasures study", BMC Public Health, 13 (808). 2013. Available from: http://www.biomedcentral.com/1471-2458/13/808.

[48] Baxter, S.D., "Cognitive processes in children's dietary recalls: insight from methodological studies", Eur J Clin Nutr, 63. S19-32. 2009. 
[49] Livingstone, M.B.E., Robson, P.J., Wallace, J.M.W., "Issues in dietary intake assessment of children and adolescents" Br J Nutr, 92 Suppl 2. S213-22. 2004.

[50] Diep, C.S., Chen, T.A., Davies, V.F., Baranowski, J.C., Baranowski, T., "Influence of Behavioral Theory on Fruit and Vegetable Intervention Effectiveness Among Children: A MetaAnalysis", J Nutr Educ Behav, 46 (6). 506-46. 2014.
[51] Eather, N., Morgan, P.J., Lubans, D.R., "Improving the fitness and physical activity levels of primary school children: Results of the Fit-4-Fun group randomized controlled trial", Prev Med, 56 (1).12-19. January 2013.

[52] Denmarks Technical University \& Steno Diabetes Center -Health Promotion Research, We Act Zone, 2016. http://www.weact.zone/. Accessed 6 ${ }^{\text {th }}$ Dec 2017. 